\title{
Analysis of Deprivations Suffered by Children Under Five in Benin
}

\author{
Fawaz A. Adéchinan Aminou ${ }^{1 *}$ and Pam Zahonogo ${ }^{2}$ \\ ${ }^{1}$ Faculty of Economics and Management, University of Abomey Calavi, Benin \\ ${ }^{2}$ Faculty of Economics and Management, University of Ouaga 2, Burkina Faso
}

(Received December 31, 2019; Accepted January 15, 2020; Published January 20, 2020)

\begin{abstract}
Children are seriously affected by poverty and suffer particular deprivations. In addition, their situation is most of the time ignored in the strategies devoted to tackling poverty. This study examined the multidimensional poverty of children under five in Benin by identifying its determinants. It used the data from the demographic and health surveys in Benin from 2011-2012 and adopted the approach by Alkire \& Foster (2011) to generate multidimensional poverty profiles of children. The weightings of the dimensions were generated by multiple correspondence analysis. The GLM and Logit models were used to identify the driving factors of child deprivation. Findings indicate that $54 \%$ of children were multidimensionally poor when the poverty line $\mathrm{k}=1$ against $32 \%$ of poor children when $\mathrm{k}=3$. Nutrition and sanitation dimensions had the highest relative contributions of 41.12 and $28.77 \%$ respectively to the global multidimensional poverty index.
\end{abstract}

Keywords: Alkire and Foster, multidimensional poverty, nutrition, health

JEL Classification: D63, I32, O10

\section{INTRODUCTION}

The issues of poverty have received particular attention from the various development actors in recent decades. In a 1972 speech on the situation of people in developing countries, the former World Bank president Robert McNamara, said that "it is time for the countries of the South to be more concerned with more basic human needs that is to improve the nutrition, housing, health, education and employment of their populations". Indeed, after a long period of macroeconomic stabilization policies contained in the structural adjustment programs which outline that governments must reduce their spending and rationalize their investment policies. The program was implemented by reducing subsidies on inputs, rationing the transport of agricultural products to reduce costs and even plunge people into poverty and underdevelopment in the short term. Donors and financial partners have become aware of the need

* Corresponding author email: mzapate2020@yahoo.fr ISSN 2615-6075 online; ISSN 2615-6946 print @UWG Press, 2020

OJS http://publishing-widyagama.ac.id/ejournalv2/index.php/jsed/ to implement social policies to combat chronic poverty. For example, the 2000 United Nations (UN) General Assembly indicated poverty reduction as a Millennium Development Goal (MDG) that placed poverty issues at the core of development strategies and academic analyzes.

However, like most of sub-Saharan Africa countries, Benin has been implementing since the advent of these MDGs in 2000 a national strategy for poverty reduction for sustainable development. The various policies implemented by the government contained in the Poverty Reduction Strategy Papers (PRSPs). The evaluation of the 2003-2005 Poverty Reduction Strategy has shown that these policies have not achieved the objectives set in terms of growth and poverty reduction.

Two other poverty reduction strategies have been developed (Growth and Poverty Reduction Strategy, 2007-2009 GPRS and 2011-2015 GPRS). The policies implemented as part of these strategies have significantly reduced the poverty rate. Indeed, the evaluation of these strategies shows that over the period 2006-2011, monetary poverty fell very slightly by $3.2 \%$ in general and in particular by $10.29 \%$ in urban areas. On the other 
hand, it increased by $2.32 \%$ in rural areas over the same period (EMICoV, 2011). Non-monetary poverty currently averages $30.2 \%$, or $32.9 \%$ in rural areas and $26.4 \%$ in urban areas. In terms of depth and severity, they are respectively 9.8 and $3.9 \%$. Worse, Beninese households estimate that they live more and more difficultly (Hounkpodote, 2009). At this rate, Benin could not certainly achieve in 2015, the MDG on halving poverty. It is therefore important to question the strategies that have been implemented to target poor people and the policies used to reduce or even eliminate both monetary and non-monetary poverty.

Research on poverty shows that women and children are most affected by poverty (Minujin et al., 2006; Nguetse Tegoum \& Hevi, 2016). Poverty begins in childhood, manifests itself in the different deprivations that they suffer and prevent them from accumulating human capital. Insufficient nutrition, poor health, lack of adult care, violence, or lack of education can have a negative impact on the physical, cognitive and psychological development of the child (Makhalima et al., 2014; Mohanty et al., 2018). Because of their education, these poor children will find it difficult to reach adulthood and to have healthy lifestyles, maintaining them into chronic poverty (Delamonica \& Minujin, 2007). Also, these children are likely to fail in accessing the improved resources needed for themselves and as parents in ensuring the best education for their children. Consequences are often irreversible and jeopardize their life (Psaki et al., 2012).

Children are the most vulnerable in society and are, for example, most affected by the incidence of poverty, especially those under fifteen. Today's children represent the adults of the future. Uneducated and malnourished, poor children are likely to become the uneducated, malnourished, poor adults of tomorrow (Bradbury, Jenkins, \& Micklewright, 2009). Thus, to reduce poverty in the future, child poverty must be addressed directly today (Fonta et al., 2019; Nguetse Tegoum \& Hevi, 2016). Similarly, child poverty is also a scourge in today's society. Reducing child poverty will reduce the misery and deprivation that children are experiencing today. To this end, it is essential to study child poverty in order to develop poverty reduction strategies that address its root causes and mitigate their effects on children. Children simply live in poverty differently from adults and are more vulnerable to its negative effects, and have more immediate needs that traditional antipoverty strategies do not respond to (UNICEF, 2012; Delamonica \& Minujin, 2007; Minujin et al., 2006). Anti-poverty strategies need to emphasize on how poverty affects children differently from adults and integrate policies that directly address child poverty.

In the search for better strategies to combat poverty, the situation of children is not sufficiently taken into account. Yet, statistics show that in Benin, children under five represent $16.5 \%$ of the population and those between 5-17 years old, $38.3 \%$ (EMICoV, 2011). And the evaluation of growth and poverty reduction strategies shows that in terms of monetary poverty, the proportion of children aged 0-17 who are poor was $41.2 ; 39.6$ and 41.3\% respectively in 2006, 2009 and 2011. These rates show that the proportion of children aged 0 to 17 living in households below the income poverty line was higher than that of the overall population. This monetary poverty was $40.1 \%$ in 2011 for children under five. This situation of the monetary poverty of children under five was more pronounced in rural areas, which has the highest proportion, around $43.3 \%$ in 2011 compared to $35.1 \%$ in urban areas. Moreover, it was $40.7 \%$ for boys against $39.4 \%$ in girls. It is therefore urgent to be aware and to evaluate the various forms of deprivations suffered by children in Benin.

There are few empirical studies on multidimensional child poverty in Benin (Hodonou, Damien, Gninanfon, \& Totin, 2012; Hounkpodote, 2009). However, none of these studies has quantified the specificities of childhood poverty and its driving factors. Therefore, there are no official statistics on the multidimensional analysis of deprivations suffered by children in Benin. This study attempts to fill this gap and its contributions will help design policies conducive to the reduction of child deprivation. The study aims at analyzing the deprivation suffered by children under five in Benin. Specifically, it aims to: (i) describe the socioeconomic characteristics of children under five, (ii) identify the dimensions of child deprivation, (iii) establish the profile of the state of 
child deprivation and (iv) identify the determinants of child deprivation.

\section{RESEARCH METHOD}

\section{Measuring Deprivation}

To analyze the deprivation of children under five in Benin, we used the approach devised by (Alkire \& Foster, 2011). It involved two steps: an identification step that identifies "who is poor" considering the range of deprivations they suffer, and aggregation step that generates a set of measures of poverty (based on traditional FosterGreer-Thorbecke, FGT measures) which can be decomposed to target the poorest people and the dimensions in which they are most deprived. It also offers two additional measures in the same class of multidimensional poverty measures: adjusted poverty gap and measurement of adjusted FGT, which are sensitive to the depth of poverty in each dimension, and inequality among the poor.

\section{Dimensions, deprivation thresholds and weighting}

The choice of the measurement dimensions of child deprivation is guided by the Sustainable Development Goals (SDGs) that defined by the United Nations which Benin is seriously committed with restrictions due to the availability of data. Thus, the Multidimensional Poverty Index is built using five dimensions (Fonta et al., 2019). The dimensions and deprivation thresholds are summarized in Table 1.

Table 1. Dimensions and Thresholds of Children Deprivation Index

\begin{tabular}{|c|c|}
\hline Dimensions & Deprived Situation \\
\hline Nutrition & $\begin{array}{l}\text { Children who are more than two standard deviations below the international reference population for } \\
\text { stunting (height for age) and wasting (weight for height) or underweight (weight for age). The } \\
\text { normalization following the algorithms provided by the baseline study of the child to the WHO growth. }\end{array}$ \\
\hline Water & Children using water from unimproved sources such as open wells, open sources or surface water \\
\hline Sanitation & $\begin{array}{l}\text { Children who use unimproved sanitation facilities such as pit latrines without slab latrine pit open, } \\
\text { hygienic bucket and suspended toilet. Surveys were normalized for comparability. }\end{array}$ \\
\hline Health & $\begin{array}{l}\text { Children who have not been vaccinated for } 2 \text { years. A child is deprived if the child has received eight of } \\
\text { the following vaccines: BCG, DTP1, DTP2, DTP3, polio0, Polio1, Polio2, polio3, measles or has not } \\
\text { received treatment for a recent illness involving respiratory infection and acute diarrhea. }\end{array}$ \\
\hline ousing & Children living in a house without floor (that is to say, a floor mud or manure) or insufficient roof \\
\hline
\end{tabular}

A challenge in the construction of the multidimensional poverty index is the choice of weights. The weight determines the intensity with which a selected variable helps explain poverty. Therefore, different weights can be assigned to each attribute. The main methods of weighting proposed in the literature include equal weights, weights based on the frequency, multivariate statistics weight (e.g. principal component analysis, the analysis in multiple correspondences), weights based on regression and normative (Decancq \& Lugo, 2009).

None of these methods have been proven to be better, and most of the approaches to measuring poverty do not provide appropriate methods to solve the weighting issue. Instead, they provide the flexibility to assign weights to each dimension normatively (Batana, 2013). Caution is also advanced on the tradeoffs that result using different methods of weighting and the need for robustness tests to determine the impact of the specific value of the weight on poverty indices (Adetola \& Olufemi, 2012). The most commonly used approach is equal weighting (Decancq \& Lugo, 2009). Although it is convenient, equal weighting is far from uncontroversial (Alkire \& Foster, 2011; Decancq \& Lugo, 2009). An equal weight is a system of normative weighting that is convenient in some situations.

The Multiple Correspondence Analysis (MCA) is the application of the analysis of simple correspondences of multi varied algorithm categorical data encoded as an indicator matrix or array of Burt. It is to explore the internal structure of a covariance matrix while producing an additive, which decreases the disintegration of the total variance (inertia) of the matrix. The MCA is designed to improve the ACP process when it loses the optimal properties of its estimates parameter and provide more powerful tools to describe the 
hidden structure in a set of variables. It is therefore appropriate for the analysis of categorical data on assets.

Thus, in this article, the weighting coefficients associated with the Dimensions were determined by a multiple component analysis (MCA) (Adetola \& Olufemi, 2012). First, all variables were returned in categorical form and the terms of each categorical variable were converted into binary dimensions taking 1 if the individual had the considered modality and 0 otherwise. Weights are calculated by dividing the factor scores for the first eigenvalue.

Once the children suffering from deprivation in each of the Dimensions identified, the next step was to determine who was multidimensionally poor. It depends on the total weighted of deprivation of each individual. We must set a second threshold, the "poverty line" $k$. In this study, we used different values of $k$ to calculate the index. Thus, a child is considered deprived if the total weighted of deprivations he suffered is greater than or equal to the threshold of deprivation $\mathrm{k}$.

\section{Econometric estimation of the determinants of child deprivation}

To identify the driving factors of child deprivation, a generalized linear regression model (GLM) was used. This choice is based on the fact that poverty indices are proportions. To study the sensitivity of these factors in the continuous or dichotomous nature of the deprivation index, we created a binary variable, 1 if the child is multidimensionally poor and 0 otherwise. We reestimated the model using the variable with a Logit model. This choice is based on the fact that this distribution facilitates the interpretation of parameters $\beta$ associated with the explanatory variables

The study used secondary data from the Demographic and Health Survey (DHS) of Benin gathered by the National Institute of Statistics and Economic Analysis in 2011-2012 including the sampling and the collection methods were presented in the first attempt. The DHS survey data are nationally representative data and they provided information on the well-being of individuals in households in general and that of children under five in particular.
The data from these surveys are cross-sectional and the key variables used in this research were: the child's age (in months), sex, education of the parents, occupation of the parent, age of household head (years), gender of the household head, the index of household wealth, household residential areas, household size, marital status of head of household and the presence a health facility.

\section{RESULT AND DISCUSSION}

This section presents the socioeconomic characteristics of children, the estimates of the deprivation indices of children and their decomposition according to the characteristics of children and the determinants of deprivation of these children.

\section{Socio-economic characteristics of children}

A classification of the children of the sample into groups of age in months shows that the within percentage is almost similar. Children between 40 49 months have the highest percentage, $18.69 \%$ with a workforce of 1348 on the total sample of children. They are followed by children of the age group $10-19$ with a percentage of $18.11 \%$, those of class $0-9$ have the lowest percentage, $14.80 \%$. The average number of children under five years is 2 per household and the average age of children under five in the household is 29.85 months. In addition, male and female children are almost equally distributed between households with 50.35 and $49.65 \%$ respectively. Finally, $36.68 \%$ of households are in urban area with about 2645 children against $63.32 \%$ in rural area with about 4566 children.

\section{Estimates of deprivation indices}

The observation of Table 2 shows that the nutrition dimension has the highest weight. This indicates that this dimension contributes the most to the explanation of the phenomenon we are studying. It is followed respectively by "Health", "Sanitation" and "Housing". The dimension of "Water" is the least significant, reflecting its low contribution in explaining the poverty of children under five years in Benin.

The estimates of children deprivation in Benin are based on five dimensions: water, sanitation, 
shelter, health and nutrition (Table 2). The estimates of children deprivation in these dimensions were made with contributions generated by the MCA. A second threshold $k$ is defined and it represents the number of dimensions in which a child should be deprived.

Table 2. Dimensions and Weight Generated by MCA

\begin{tabular}{lc}
\hline Dimensions & MCA weight \\
\hline Water & 0,074 \\
Sanitation & 1,517 \\
Housing & 0,145 \\
Health & 1,628 \\
Nutrition & 0,183 \\
\hline
\end{tabular}

Source: Estimates from EDS data 2011-2012

Table 3 shows the index of multidimensional deprivation estimated according to the value of the threshold $k$. It results from this table that the measures of privations reduce in respect to the level of $k$. It is consistent with the findings of Adetola \& Olufemi (2012), Batana (2013), and Kabubo-Mariara, Wambugu, \& Musau (2012). When the number of deprivations suffered by children $\mathrm{k}$ is 1 , the incidence rate $\mathrm{H}$ is $96.3 \%$ and $41.1 \%$ for $\mathrm{k}=$ 3. This result is similar to the incidence rate of Bangladesh and Nigeria which gave 96\% respectively (Budd, 2001) and $90.9 \%$ of (Adetola \& Olufemi, 2012) children deprived multidimensionally for $\mathrm{k}=1$. By contrary, it is different from the $41.2 \%$ found by (Kabubo-Mariara et al., 2012) among Kenyan children for $\mathrm{k}=1$.

Table 3. Multidimensional Deprivation Index of Children

\begin{tabular}{lcccc}
\hline K) & $\left(M_{0}=H A\right)$ & $(\mathrm{H})$ & $(\mathrm{A})$ & $\begin{array}{c}\text { Average } \\
\text { deprivation }\end{array}$ \\
\hline $\mathrm{K}=1$ & 0.540 & 0.963 & 0.561 & 2.805 \\
$\mathrm{~K}=2$ & 0.485 & 0.748 & 0.648 & 3.240 \\
$\mathrm{~K}=3$ & 0.320 & 0.411 & 0.777 & 3.885 \\
$\mathrm{~K}=4$ & 0.102 & 0.108 & 0.946 & 4.730 \\
$\mathrm{~K}=5$ & 0.030 & 0.030 & 1.000 & 5.000 \\
\hline
\end{tabular}

Source: Estimates from EDS data 2011-2012

The adjusted incidence rate also suggests that 54 and $32 \%$, respectively, for $\mathrm{k}=1$ and $\mathrm{k}=3$, children are deprived. A similar result was obtained for rural children in Nigeria where 52 and $27.9 \%$ of children are deprived multidimensionally respectively for $\mathrm{k}=1$ and $\mathrm{k}=3$ (Adetola \& Olufemi, 2012). Alkire \& Roche (2012) also found a result not too far for children in Bangladesh with 48.7 and $40 \%$ for $k=1$ and $k=3$, respectively. Kabubo-Mariara et al., (2012) have meanwhile found different results for rural children in Kenya with 24.2 and $4.9 \%$ for $k=1$ and $k=3$, respectively.

The intensity of deprivation indicates that the proportion of dimensions in which the privations of victims are denied increases with $\mathrm{k}$. Although the index of multidimensional deprivation (MDI) of children decreases because the number of children in poverty decreases, the intensity of the deprivations of the poor increases. This is consistent with the findings of Alkire \& Roche, (2012).

The average deprivation among children who are deprived in at least one dimension of size 2,805 and between children who are deprived in at least three dimensions $(k=3)$, it is 3,885 . These results are consistent with those of (Adetola \& Olufemi, 2012) where the mean deprivation among children was 2.86 for $k=1$ and $k=3.81$ for 3 . (Alkire \& Roche, 2012) also found that it is 3.03 to 3.67 and $\mathrm{k}=1$ to $\mathrm{k}=3$.

The relative contribution of different dimensions to the overall deprivation is presented in Table 4. The results show that the dimension nutrition has the greatest contribution with $41.12 \%$ at $\mathrm{k}=1$. It is followed by dimension sanitation with $28.7 \%$ at $\mathrm{k}$ $=1$, whereas the dimension water has the lowest contribution with $2.76 \%$. Similar results were obtained with $\mathrm{k}=2$ and $\mathrm{k}=3$. This finding implies that nutrition and sanitation of children should be a policy target to reduce child poverty in Benin.

Table 4. Relative Contributions of Dimensional MDI Children

Dimensions Water Sanitation Housing Health Nutrition

\begin{tabular}{|c|c|c|c|c|c|}
\hline $\mathrm{K}=1$ & 2.76 & 28.77 & 11.54 & 15.81 & 41.12 \\
\hline$K=2$ & 2.62 & 31.03 & 14.44 & 16.70 & 35.21 \\
\hline$K=3$ & 2.43 & 28.15 & 20.57 & 17.76 & 31.09 \\
\hline$K=4$ & 2.08 & 23.10 & 22.10 & 24.80 & 27.92 \\
\hline$K=5$ & 7.40 & 21.85 & 20.90 & 23.45 & 26.40 \\
\hline
\end{tabular}

Source: Estimates from EDS data 2011-2012

\section{Decomposition of Child Deprivation}

The breakdown of child poverty by sex for the various possible thresholds shows that male children are more victims of deprivation than female children. However, the difference between the sexes is non-significant. Table 5 presents the poverty indices by sex. It results that $54.4 \%$ of 
male children are multidimensionally poor to $\mathrm{k}=1$ against $53.6 \%$ of female. This rate was $32.7 \%$ against $31.1 \%$ at $\mathrm{k}=3$. These results are similar to those obtained by Adetola \& Olufemi (2012), where $52.6 \%$ of male and $51.7 \%$ of female are poor at $k$ $=1$. However, the intensity of poverty is higher among male children than female. This shows that male children are more deprived compared to female children. However, this result opposes the conclusion of Adetola \& Olufemi (2012) for the case of Nigeria.

Table 5. Decomposition of Child Deprivation Indices by Sex and Resident

\begin{tabular}{lcccccc}
\hline \multirow{2}{*}{ Poverty line } & \multicolumn{3}{c}{$\mathrm{K}=1$} & \multicolumn{3}{c}{$\mathrm{K}=3$} \\
\cline { 2 - 7 } & $M O$ & $H$ & $A$ & $M O$ & $H$ & $A$ \\
\hline Sex & & & & & & \\
$\quad$ Male & 0.544 & 0.963 & 0.565 & 0.327 & 0.420 & 0.780 \\
$\quad$ Female & 0.536 & 0.962 & 0.558 & 0.311 & 0.403 & 0.772 \\
Residence & & & & & & \\
$\quad$ Rural & 0.612 & 0,990 & 0.619 & 0.421 & 0.542 & 0.777 \\
$\quad$ Urban & 0,425 & 0.919 & 0.463 & 0,160 & 0,207 & 0.773 \\
\hline Source: Estimates from EDS data 2011-2012 &
\end{tabular}

The decomposition of deprivation indices by residence indicates that children living in rural areas suffer more deprivation than those in urban. Table 5 shows that $61.2 \%$ of children living in rural areas are multidimensionally deprived against $42.5 \%$ of urban children at $\mathrm{k}=1$. These rates are 42.1 and $16 \%$ respectively for $k=3$. These results can be explained by the fact that urban areas are characterized by best roads, health, education, etc. compared to rural areas so that children in households living in rural areas are deprived of a significant number of dimensions, which makes them more vulnerable. The intensity of deprivation is lower in urban than rural children.

\section{Determinants of deprivation of children}

Table 6 presents estimates results of GLM and Logit models of the determinants of deprivation of children under five years in Benin. First of all, we ran a GLM directly using the estimated values of child deprivation indices at $\mathrm{k}=2$, corresponding to $40 \%$ of the dimensions considered. To analyze the robustness of the results of the first model, we created a binary variable, and MDI obtained for $\mathrm{k}=$ 2 (0.485) was selected as a threshold for identifying the poor and non-poor children. Thus, a Logit model was estimated and the test for the likelihood ratio (Prob (chi 2) $=0.000$ ) shows that the overall model is significant at $1 \%$.

\section{Effect of child characteristics}

The coefficients of different children's age groups are negatively correlated with the probability that a child is multidimensionally deprived compared to the class 0-9 months. However, only the coefficients of the class 20-29 months are significant at $5 \%$ in both models and that of the $10-19$ class is significant at $5 \%$ only in the logit model. It shows that as far as the age of the child increases (class 0-9 months to the next), the probability of deprivation decreases. The estimated marginal effect shows that the probability that a child of the age group 20-29 months or multi-dimensionally deprived is reduced respectively by 0.015 and 0.061 percentage in both models. This result shows that special attention should be given to younger children because they are more likely to experience deprivation. Thus, the information should be given to people, particularly women with newborns on such different vaccinations that children should take and the women need to conform the standard that must be taken.

The sex of a child influence significantly positively at $1 \%$, the probability that the child is deprived when going from a boy child to a girl. The male influences positively and significantly the probability that the child is deprived of our two models. This result is consistent with that found by Adetola \& Olufemi (2012), but in their case, the coefficient is not significant. However, this can be in the line of studies showing that male children surpass female at birth but over time female surpasses male. It shows that male is more demanding children in care than girls. It should be noted that this probability increases, respectively by 0.0132 and 0.035 in both models when going from a female child to a male child. It shows that awareness campaigns should be directed towards women with male infants. 
Table 6. Estimated Determinants of Child Deprivation

\begin{tabular}{|c|c|c|c|}
\hline \multirow{2}{*}{ Variables } & \multirow{2}{*}{$\begin{array}{c}\text { GLM } \\
\text { Coefficients }\end{array}$} & \multicolumn{2}{|c|}{ Logit model } \\
\hline & & Coefficients & Marginal effects \\
\hline \multicolumn{4}{|l|}{ Child age in months } \\
\hline $0-9$ & & Control & \\
\hline $10-19$ & $-0.0096 * * *(0.007)$ & $-0.1978(0.101)$ & $-0.0489 * *(0.025)$ \\
\hline $20-29$ & $-0.0150 * * *(0.007)$ & $-0.2477 *(0.099)$ & $-0.0611 *(0.024)$ \\
\hline $30-39$ & $-0.0119 * * *(0.007)$ & $-0.1470 *(0.100)$ & $-0.0364 * *(0.025)$ \\
\hline $40-49$ & $-0.0070 * * *(0.007)$ & $-0.1505 *(0.097)$ & $-0.0373 * *(0.024)$ \\
\hline $50-59$ & $-0.0011 * * *(0.007)$ & $-0.0587(0.102)$ & $-0.0146 * *(0.025)$ \\
\hline \multicolumn{4}{|l|}{ Child's Sex } \\
\hline Female & & Control & \\
\hline Male & $0.0132 * * *(0.004)$ & $0.1405 *(0.056)$ & $0.0350 * *(0.014)$ \\
\hline \multicolumn{4}{|l|}{ Education of mother } \\
\hline No & & Control & \\
\hline Primary & $-0.0144 * * *(0.006)$ & $-0.1109 *(0.081)$ & $-0.0275^{* *}(0.020)$ \\
\hline Secondary & $-0.0216 * * *(0.007)$ & $-0.2231(0.116)$ & $-0.0550 * *(0.028)$ \\
\hline Superior & $-0.0146 * *(0.017)$ & $-0.0743(0.425)$ & $-0.0184(0.105)$ \\
\hline \multicolumn{4}{|l|}{ Father Education } \\
\hline No & & Control & \\
\hline Primary & $-0.0097 * * *(0.005)$ & $-0.0848 *(0.074)$ & $-0.0211 * *(0.018)$ \\
\hline Secondary & $-0.0247 * * *(0.006)$ & $-0.2699 *(0.090)$ & $-0.0665 * *(0.022)$ \\
\hline Superior & $-0.0080 * *(0.015)$ & $-0.0975(0.223)$ & $-0.0242 *(0.055)$ \\
\hline \multicolumn{4}{|c|}{ Partner Occupation of head of household } \\
\hline Professional & $-0.0129 * * *(0.008)$ & $-0.2812(0.116)$ & $-0.0692 * *$ \\
\hline Sale & $0.0157 * *(0.010)$ & $0.2059(0.137)$ & $0.0514 * *(0.034)$ \\
\hline Agriculture & $-0.0156 * * *(0.006)$ & $-0.2554 * *(0.082)$ & $-0.0634 * *(0.020)$ \\
\hline Service & $-0.0067 * * *(0.007)$ & $-0.0938 *(0.096)$ & $-0.0233 * *(0.023)$ \\
\hline Other & & Control & \\
\hline \multicolumn{4}{|c|}{ Household characteristics Gender of the household head } \\
\hline Female & & Control & \\
\hline Male & $0.0248 * * *(0.007)$ & $0.3147 *(0.099)$ & $0.0772 * *(0.024)$ \\
\hline \multicolumn{4}{|c|}{ Age of household head in year } \\
\hline Less than 25 & $-0.0181 * *(0.017)$ & $-0.3417(0.207)$ & $-0.0834 *(0.051)$ \\
\hline $25-39$ & $-0.0106 * *(0.012)$ & $-0.3033(0.151)$ & $-0.0754 * *(0.038)$ \\
\hline $40-54$ & $-0.0117 * *(0.012)$ & $-0.2650(0.161)$ & $-0.0656 * *(0.040)$ \\
\hline $55-69$ & $-0.0191 * *(0.014)$ & $-0.3071(0.198)$ & $-0.0753 * *(0.047)$ \\
\hline 70 and more & & Control & \\
\hline \multicolumn{4}{|l|}{ Wealth index } \\
\hline Poorest & & Control & \\
\hline Poorer & $-0.0687 * * *(0.006)$ & $-1.1902 *(0.093)$ & $-0.2744 * *(0.019)$ \\
\hline Middle & $-0.1454 * * *(0.006)$ & $-2.2889 *(0.094)$ & $-0.4632 * *(0.014)$ \\
\hline Richer & $-0.1816 * * *(0.007)$ & $-2.9827(0.109)$ & $-0.5424 * *(0.013)$ \\
\hline Richest & $-0.2218^{* * *}(0.008)$ & $-3.3524(0.134)$ & $-0.5454 * *(0.012)$ \\
\hline \multicolumn{4}{|l|}{ Household size } \\
\hline $1-3$ & $-0.0031 * * *(0.009)$ & $-0.1746 *(0.085)$ & $-0.0432 * *(0.022)$ \\
\hline $4-5$ & $-0.0021 * * *(0.006)$ & $-0.0536 *(0.083)$ & $-0.0133 * *(0.021)$ \\
\hline $6-8$ & $-0.0004 * * *(0.005)$ & $-0.0221 *(0.075)$ & $-0.0055 * *(0.019)$ \\
\hline 8 and more & & Control & \\
\hline \multicolumn{4}{|c|}{ Marital status of head of household } \\
\hline Never in union & $-0.0039 * *(0.016)$ & $0.0102(0.243)$ & $0.0025 *(0.061)$ \\
\hline Married & $0.0024 * * *(0.005)$ & $-0.0752 *(0.070)$ & $-0.0187 * *(0.017)$ \\
\hline Widower & $-0.0235 * *(0.020)$ & $-0.4186(0.277)$ & $-0.1013 *(0.064)$ \\
\hline Divorced & $-0.0256 * *(0.030)$ & $0.0016(0.432)$ & $0.0004(0.108)$ \\
\hline \multicolumn{4}{|l|}{ Health facility } \\
\hline Yes & $-0.0120 * * *(0.004)$ & $-0.1569 *(0.058)$ & $-0.0390 * *(0.014)$ \\
\hline Constant & $0.7630 * *(0.016)$ & $2.2549(0.232)$ & \\
\hline Number of Observations & 5595 & 7211 & 7211 \\
\hline Log pseudolikehood & 2792.171669 & -3913.0425 & \\
\hline Wald chi 2 (33) & & 1575.24 & \\
\hline Pseudo R2 & & 0.2148 & \\
\hline
\end{tabular}




\section{Effect of parental characteristics}

The estimates of the education level were made, taking as reference "no level". The coefficient associated with households whose mothers have a secondary level of education is significant and negative at 1\% (GLM model) and $10 \%$ (logit model). This implies that the probability that a child is multidimensionally deprived decreases with the education level of the mother. A mother with a high school attendance reduced that probability by 0.0216 point (GLM model) and 0.055 point (logit model).

Father's level of education also significantly reduced at $1 \%$, the probability of a child being deprived. A father with a secondary level has a higher marginal effect. Indeed, it reduces the probability that a child is deprived of 0.0247 and 0.0665 points respectively in the two models. This shows that children's deprivation decreases with the education level of parents. Similar results were reported by Adetola \& Olufemi (2012) in studies on children in Nigeria. These results are explained by the fact that an increase in the education of the poor tends to reduce the cycle of poverty because the work is by far the most important factor of the poor (Adetola \& Olufemi, 2012). Of course, schooling is a long-term investment, but these results underestimate the long-run importance of children's education in reducing poverty in Benin.

Regarding the occupation of household heads partner, the probability that a child is deprived significantly lower with professional partners and those working in agriculture as shown in a negative correlation with the probability that the child is deprived multidimensionally compared to other occupations. For partners of parents who are professionals, the probability that the child is multidimensionally deprived decreases by 0.0129 and 0.0691 points respectively in the two models, while for those engaged in agriculture, it decreases by 0.0156 and 0.0634 points respectively in the two models. This result shows that the agricultural sector does not yet allow the person exercising in this sector to have a standard of living compared to one who is not in that sector. Thus, policies should be implemented to further enhance the agricultural sector to enable those working in it to improve their income and therefore their welfare and that of their entire family.

\section{Effect of household characteristics}

The probability that a child is deprived is higher when the household head is a man rather than a woman. A household headed by a man is positively correlated with the likelihood that a child's household is deprived and significant at $1 \%$. This result opposes that found by Adetola \& Olufemi (2012). However, this can be justified by the fact that women usually run smaller households whereas men are leading large households. Also, women are more available and closer to children. Also, they seem to take better care of children compared to men. The estimated marginal effect shows that the probability of a child being deprived increases in both models by 0.0248 and 0.0772 respectively when moving from a female-headed household to a male-headed household.

The probability that a child is multidimensionally deprived increases with the age of the household head (significantly at $5 \%$ and $10 \%$ but only in the logit model). This is consistent with the a priori expectation that poverty increases with age since the productivity of the individual decreases. This result is in accordance with the study of (Adetola \& Olufemi, 2012). The estimated marginal effect shows that the probability that the child is deprived decreases 0.0753 point when moving from the age group of 70 and over in the $25-39$ class and 0.0834 when passing to the class of less than 25 years. This result implies that insurance policies must be implemented to reduce the declining revenue of parents due to retirement.

As for the wealth index quintile, all coefficients of different categories of wealth are important and significant to $1 \%$ in both models compared to the reference category "Poorest". These variables are negatively correlated with the probability that a child is deprived. This shows that as far as household wealth increases, the probability that a living child will be deprived decreases. The estimated marginal effect shows that the probability that a "Richest" household child is multidimensionally deprived is reduced by 0.2218 and 0.5454 points in both models compared to a child living in a "Poorest" household.

Household size positively affects the probability of a child of this household is multidimensionally deprived. This correlation is significant in the 
second model in class 1-3. This shows that when moving from a large household to a smaller (1-3 people), the probability that the child under five years is poor decreased by 0.0431 point. This position is consistent with that of Hounkpodote (2009), that argued that small households are less likely to be poor than others. It only confirms the need to set up incentive mechanisms that cause households to limit the number of births in a home.

The presence of a health facility also reduces the likelihood that a child is multidimensionally deprived as shown negative correlation which is significant at $5 \%$. The impact of the presence of a health center in the community reduces the likelihood that a child is multidimensionally deprived by 0.009 and 0.034 points, respectively in the two models. This result is explained by the fact that this health facility facilitates household access to health services such as sensitization on the necessary vaccinations for children, on the nutrition of children, and the kind. These results are consistent with those obtained by Adetola \& Olufemi (2012). This shows that programs decentralization of health facilities on the national territory must be continued and must be accompanied by recruitment and training of new health workers.

\section{CONCLUSION AND SUGGESTION}

The study showed that the Alkire and Foster index estimates depend on the number of dimensions considered, and the measure of deprivation decreases with the value of the threshold $k$. The dimension nutrition has been identified as one that contributes most to the multidimensional child poverty in Benin. This indicates that women should be educated especially in rural areas on the impact of nutrition on the wellbeing of children today but also in the future. The multidimensional deprivation index of children is 0.485 with an almost equal relative contribution of both sexes to the overall multidimensional deprivation index.

Identifying determinants of deprivations suffered by children revealed that the age, sex, the education level of parents, households headed by women, small households, household wealth, professional and agricultural sector head of household's partner, and the presence of health facility reduce the likelihood that a child is multidimensionally poor. By contrary, households headed by men, the high age of the household head and the male child increased the likelihood that a child is multidimensionally poor. These different determinants were found to be robust to the dichotomous nature or otherwise of the multidimensional poverty index, with the exception of the age of the household head and household size.

The eradication of child poverty, in particular, should use a variety of measures affecting different dimensions since poverty is a multidimensional phenomenon. These include more awareness of mothers for improved child nutrition and the various vaccinations that children should take before their five years. It should also encourage the provision of more health facilities. Promoting the construction of social housing in both urban and rural areas and making it available primarily to the neediest households, since attention must be paid to the housing dimension. Finally, to promote access to the family planning program, which is an essential key to reducing household size and poverty.

\section{REFERENCES}

Adetola, A., \& Olufemi, P. (2012). Determinants of Child Poverty in Rural Nigeria: A Multidimensional Approach. Global Journal of Human Social Science Arts \& Humanities, 12(12), 1-17. Retrieved from https://pdfs.semanticscholar.org/9d43/26c4573 a6a727a7ab9f3b511c93631fad61f.pdf

Alkire, S., \& Foster, J. (2011). Counting and multidimensional poverty measurement. Journal of Public Economics, 95(7-8), 476-487. https://doi.org/10.1016/j.jpubeco.2010.11.006

Alkire, S., \& Roche, J. M. (2012). Beyond headcount: Measures that reflect the breadth and components of child poverty. In Global child poverty and well-being: Measurement, concepts, policy and action (pp. 103-134). Policy

Press. https://doi.org/10.1332/policypress/978184742 $\underline{4822.003 .0005}$

Batana, Y. M. (2013). Multidimensional Measurement of Poverty Among Women in SubSaharan Africa. Social Indicators Research, 112(2), 337-362. https://doi.org/10.1007/s11205-013-0251-9 
Bradbury, B., Jenkins, S. P., \& Micklewright, J. (2009). The dynamics of child poverty in seven industrialised nations. In The Dynamics of Child Poverty in Industrialised Countries (pp. 92132). Cambridge University Press. https://doi.org/10.1017/cbo9780511522147.004

Budd, L. (2001). Child poverty in the developing world. Trends in Parasitology, 17(5), 215. https://doi.org/10.1016/s1471-4922(0.1)01963$\underline{8}$

Decancq, K., \& Lugo, M. A. (2009). Setting Weights in Multidimensional Indices of Well-being and Deprivation. OPHI Working Paper 18. https://doi.org/10.1525/fq.1998.52.2.04a00090

Delamonica, E. E., \& Minujin, A. (2007). Incidence, depth and severity of children in poverty. Social Indicators Research, 82(2), 361-374. https://doi.org/10.1007/s11205-006-9039-5

EMICoV. (2011). Integrated Modular Survey on Households Living Conditions 2011. Benin. Retrieved from https://www.ilo.org/surveydata/index.php/ddibr owser/454/export/?format=pdf\&generate=yes

Fonta, W. M., Nkwenkeu, S. F., Lath, M., Hollebecque, A., Ouedraogo, B., \& Sirajo, S. (2019). Multidimensional Poverty Assessment among Adolescent Children in the Mouhoun Region of Burkina Faso, West Africa. Child Indicators Research, 12(4), 1287-1318. https://doi.orq/10.1007/s12187-018-9575-y

Hodonou, A., Damien, M., Gninanfon, A., \& Totin, A. (2012). Poverty Dynamics in Benin: A Markovian Process Approach (Dynamique De La Pauvrete AU Benin: Approche Par Le Processus Markovien). SSRN Electronic Journal. https://doi.org/10.2139/ssrn.1674633

Hounkpodote, H. (2009). Multidimensional Analysis of Poverty in Benin: A Fuzzy Subsets Approach Analyse Multidimensionnelle De La Pauvrete Au Benin: Une Approche Par Les Sous Ensembles Flous. Munich . Retrieved from https://mpra.ub.unimuenchen.de/27005/1/MPRA paper 27005.pdf

Kabubo-Mariara, J., Wambugu, A., \& Musau, S. (2012). Multdimensional Poverty in Kenya: Analysis of Maternal and Child Wellbeing. SSRN Electronic Journal.
Makhalima, J. L., Sekatane, M. B., \& Dunga, S. H (2014). Determinants of Child Poverty in a South African Township: A Case of Boipatong Township. Mediterranean Journal of Social Sciences, 5(5), 235-241. https://doi.org/10.5901/mjss.2014.v5n1p235

Minujin, A., Delamonica, E., Davidziuk, A., \& Gonzalez, E. D. (2006). The definition of child poverty: A discussion of concepts and measurements. Environment and Urbanization, $18(2)$, 481-500. https://doi.org/10.1177/0956247806069627

Mohanty, S. K., Rasul, G., Mahapatra, B., Choudhury, D., Tuladhar, S., \& Valdemar Holmgren, E. (2018). Multidimensional Poverty in Mountainous Regions: Shan and Chin in Myanmar. Social Indicators Research, 138(1), 23-44. https://doi.org/10.1007/s11205-017$\underline{1662-9}$

Nguetse Tegoum, P., \& Hevi, K. D. (2016). Child Poverty and Household Poverty in Cameroon: A Multidimensional Approach. In Economic Studies in Inequality, Social Exclusion and WellBeing (pp. 11-33). Springer. https://doi.org/10.1007/978-3-319-30981-1 2

Psaki, S., Bhutta, Z. A., Ahmed, T., Ahmed, S., Bessong, P., Islam, M., ... Checkley, W. (2012). Household food access and child malnutrition: Results from the eight-country MAL-ED study. Population Health Metrics, 10. https://doi.org/10.1186/1478-7954-10-24

UNICEF. (2012). State of the World's Children 2012: Children in an Urban World. The state of world's children 2012. Retrieved from http://www.unicef.org/sowc2012/pdfs/SOWC 2012-Main Report EN 13Mar2012.pdf

United Nations. (2003). Indicators for monitoring the Millennium Development Goals. Definitions, rationale, concepts and sources. [Statistical papers] / United Nations, Department of Economic and Social Affairs, Statistics Division: Ser[ies] F ; 95.

WHO. (2006). WHO Child Growth Standards. Geneva. Retrieved from https://www.who.int/childgrowth/standards/Tec hnical report.pdf https://doi.org/10.2139/ssrn.1935594 